\title{
NANOPARTÍCULAS CASCA-NÚCLEO E LIGA DE PtPb/C: ESTUDO COMPARATIVO DA ATIVIDADE ELETROCATALÍTICA PARA REAÇÃO DE OXIDAÇÃO DE ETANOL
}

\author{
L. S. R. Silva ${ }^{1}$, L. P. da $\operatorname{Costa}^{1}$, R. S. Silva ${ }^{2}$, K.I.B. Eguiluz ${ }^{1}$, G.R. Salazar-Banda ${ }^{1}$ \\ ${ }^{1}$ Laboratório de Eletroquímica e Nanotecnologia, Instituto de Tecnologia e Pesquisa / \\ Programa de Pós-graduação em Engenharia de Processos, Universidade Tiradentes \\ ${ }^{2}$ Universidade Federal de Sergipe, Departamento de Física \\ Lays.reis@yahoo.com.br
}

\begin{abstract}
RESUMO - Nanopartículas casca-núcleo de Pt:Pb em proporções (3:1), (2:1), (1:1) e (1:2), liga (3:1), foram sintetizadas por um processo de redução sucessiva dos sais $\mathrm{PbCl}_{2}$ e $\mathrm{H}_{2} \mathrm{PtCl}_{6} 6 \mathrm{H}_{2} \mathrm{O}$ utilizando $\mathrm{H}-\mathrm{COOH}$ como redutor. $\mathrm{O} \mathrm{Pt} / \mathrm{C}_{\mathrm{MRS}}$ (MRS - método de redução sucessiva) também foi sintetizado para comparação. Resultados eletroquímicos mostraram que o eletrocatalisador $\mathrm{Pt}_{3} @ \mathrm{~Pb} / \mathrm{C}$ exibiu perfil característico de Pt pura, sugerindo a formação da estrutura casca-núcleo. E imagens de MET mostraram, para essa estrutura, diâmetro médio de $\pm 2,62 \mathrm{~nm}$. Este catalisador apresentou potencial de início de oxidação de $0,52 \mathrm{~V}$, enquanto que um valor de $0,57 \mathrm{~V}$ foi encontrado para o $\mathrm{Pt}_{3} \mathrm{~Pb} / \mathrm{C}$, indicando que o efeito catalítico está claramente relacionado aos efeitos eletrônico e geométrico induzidos pelos átomos de $\mathrm{Pb}$ presentes na estrutura. Assim, liberando sítios ativos de $\mathrm{Pt}$ para as reações de oxidação de etanol, levando a oxidação a potenciais baixos. Experimentos de FTIR mostraram bandas de $\mathrm{CO}_{2}$ iniciando a partir de $0,8 \mathrm{~V}$ para $\mathrm{Pt}_{3} @ \mathrm{~Pb} / \mathrm{C}$, enquanto que para os demais catalisadores conversões a $\mathrm{CO}_{2}$ somente foram observadas em potenciais acima de $1,1 \mathrm{~V}$. Mostrando assim facilidade de quebra da ligação $\mathrm{C}-\mathrm{C}$ neste catalisador, o que é uma pré-condição para a oxidação completa do etanol a $\mathrm{CO}_{2}$.
\end{abstract}

\section{INTRODUÇÃO}

Com o objetivo de alcançar níveis práticos de corrente e reduzir os custos de produção, principalmente na geração de energia de pequeno porte e sistemas portáteis, iniciativas recentes de grupos de pesquisas e indústrias têm focado seus trabalhos em células a combustível de etanol direto (CCED), mostrando-se um sistema relativamente compacto, e com maiores densidades de energia quando comparado a outras tecnologias existentes (Kajikawa et al., 2008).

No entanto, obstáculos, tais como a cinética da reação de oxidação de etanol relativamente pobre e a desativação do catalisador devido à oxidação do álcool sobre catalisadores de platina, que gera produtos intermediários, como $\mathrm{CO}$ que pode ser adsorvido 
sobre a superfície de Pt, ainda dificultam a comercialização generalizada destes dispositivos (Zhou et al., 2005). Neste contexto, o desenvolvimento de catalisadores altamente ativos para as células a combustível tem-se estendido a partir de catalisadores do grupo da Pt para catalisadores tradicionais de ligas de Pt a materiais em escala nanométrica.

Desenvolver nanopartículas (NP) com diferentes morfologias e estruturas de superfície pode fornecer uma grande oportunidade para melhorar as suas propriedades catalíticas e reduzir o uso de platina (Liang Wang et al., 2011). Na maioria dos casos, a Pt é utilizada sob a forma de pequenas NP, com o objetivo de maximizar a utilização do metal, resultando em área de superfície elevada, que é especialmente essencial para aplicações na catálise (Koh et al., 2007). Outra forma eficaz de reduzir o uso da Pt é fazer ligas com um segundo ou terceiro metal, o que é uma forma conveniente para modificar as propriedades eletrocatalíticas da platina, a fim de superar o envenenamento e a diminuição do seu uso (Geng et al., 2009). Uma segunda opção, seria combinar Pt com uma base de metal, o que cria uma estrutura de nanopartículas de catalisadores com um núcleo de metal base e casca de Pt (Kristian e Wang, 2008). É relatado que a organização de metais nobres com cascas finas (idealmente monocamadas) em núcleos de outros metais não só reduzem grandemente sua utilização, mas também melhora significativamente as suas propriedades catalíticas através da chamada tensão dos efeitos ligantes do metal núcleo com metal nobre que constituí o invólucro (Chen et al., 2008).

Catalisadores metálicos (por exemplo, $\mathrm{Pb}$ ) cobertos por cascas de Pt surgiram neste trabalho como uma classe intrigante de nanopartículas casca-núcleo, onde a importância deriva em grande parte do desenvolvimento de materiais funcionais de fácil estabilidade, capacidade de auto-organização atômica, com reações envolvendo características ópticas, eletrônicas e magnéticas. Esta motivação é inspirada na descoberta de atividades catalíticas de partículas menores do que $5 \mathrm{~nm}$ em alguns trabalhos (Sasaki et al., 2011) e a abundante demonstração de vários nanomateriais de Pt com diferentes formas que foram sintetizados com sucesso, tal como Pt poliédrica, nanofios e nanoestruturas core-shell (Garam et al., 2011).

Neste trabalho, com o intuito de diminuir a carga de catalisadores à base de $\mathrm{Pt}$ e para aumentar a sua atividade, um catalisador com estrutura casca-núcleo, $\mathrm{Pb} @ \mathrm{Pt} / \mathrm{C}$, foi rapidamente produzido através de processos de reduções sucessivas. Em comparação com a Pt pura e catalisadores liga $\mathrm{PtPb}$. O catalisador preparado, $\mathrm{Pt} @ \mathrm{~Pb} / \mathrm{C}$, não só exibe significativamente aumento da atividade catalítica para a oxidação de etanol, mas também melhora a utilização da Pt. Os desempenhos frente à oxidação de etanol mostram sua grande promessa pra resolver o problema da alta demanda por metais nobres nos ânodos das CCEDs.

O tamanho das partículas foram caracterizadas por microscopia eletrônica de transmissão (MET), difração de raios X (DRX), e por um dos métodos mais modernos de espectroscopia in situ como FTIR foi empregado para identificar os intermediários formados na superfície do catalisador. As propriedades eletroquímicas dos suportes foram caracterizadas por técnicas eletroquímicas utilizando um potenciostato. 


\section{Metodologia}

\section{$2.1 \quad$ Procedimentos experimentais}

As nanopartículas $\mathrm{Pt} @ \mathrm{~Pb} / \mathrm{C}$ foram sintetizadas por meio de um processo sequencial. $\mathrm{O}$ $\mathrm{Pb}\left(\mathrm{PbCl}_{2}\right.$, Sigma-Aldrich), foi inicialmente reduzido na presença de ácido fórmico $(\mathrm{HCOOH}$, 98-100 \% , Vetec $^{\circledR}$ ) convertendo seu estado iônico em átomos metálicos. Em segundo lugar, adicionou-se uma solução contendo $\left(\mathrm{H}_{2} \mathrm{PtCl}_{6} \cdot 6 \mathrm{H}_{2} \mathrm{O}, \geq 37.5 \%\right.$ em base de Pt, Sigma-Aldrich), para reagir com átomos de $\mathrm{Pb}$ e formar uma camada de $\mathrm{Pt}$ em torno dos núcleos de $\mathrm{Pb}$. Em seguida, foi adicionada uma quantidade apropriada de carbono Black (Alfa Aesar/Acetylene, $99.9 \%$ - A Johnson Matthey Company) para atingir uma carga total de metal de $20 \%$, e a solução final agitada lentamente por $24 \mathrm{~h}$. Uma agitação contínua, foi necessária para a formação de núcleos. O catalisador suportado em carbono foi centrifugado a $2000 \mathrm{rpm}$ utilizando um sistema CENTRIBIO, 80-2BSN. No último estágio de síntese o pó foi lavado com água ultrapura (MILLI-Q) do sistema (Millipore), submetido à filtragem a vácuo e posteriormente seco a $70^{\circ} \mathrm{C}$ durante $2 \mathrm{~h}$. Os eletrocatalisadores ligas foram sintetizados por um procedimento similar. Partindo da adição conjunta dos precursores metálicos $\mathrm{H}_{2} \mathrm{PtCl}_{6} \cdot 6 \mathrm{H}_{2} \mathrm{O}$ e $\mathrm{PbCl}_{2}$. Os metais foram depositados em carbono Black com o uso de $\mathrm{HCOOH}$, resultando em nanopartículas de $\mathrm{PbPt} / \mathrm{C}$. O pó obtido foi recuperado com descrito acima.

O tamanho e a morfologia das partículas de $\mathrm{PtPb} / \mathrm{C}$ e catalisadores $\mathrm{Pt} @ \mathrm{~Pb} / \mathrm{C}$ foram analisadas por microscopia de transmissão (MET), modelo JEOL 2100 HTP JEM operando a $200 \mathrm{KV}$. A nanopartículas foram tratadas pelo software Imagem Tool, a partir da contagem de 100, 120 e 270 partículas, para $\mathrm{Pt}_{3} @ \mathrm{~Pb} / \mathrm{C}, \mathrm{Pt} @ \mathrm{~Pb} / \mathrm{C}$ e $\mathrm{Pt}_{2} @ \mathrm{~Pb} / \mathrm{C}$, respectivamente. A transformada de Fourier de infravermelhos (FTIR) foi utilizada para investigar os produtos formados durante a oxidação do álcool nas reações química da superfície das nanopartículas. Os espectros foram investigados em janela de $\mathrm{CaF}_{2}$ em um instrumento NICOLET 6700 sistema (Thermo, Scientific). Os padrões dos difratogramas de raios $\mathrm{X}$ para os catalisadores $\mathrm{Pt} / \mathrm{C}, \mathrm{PtPb} / \mathrm{C}$ e Pt@Pb/C foram obtidos em um difratômetro de raios X (RIGAKU modelo ULTIMA UNIVERSAL + RINT 2000/PC) operando com a radiação $\mathrm{Cu} \mathrm{K}_{\alpha}(\lambda=0,15406 \mathrm{~nm})$ com padrões de difração gerados a $40 \mathrm{KV}$ e $40 \mathrm{~mA}$, com velocidade de $2^{\circ} \mathrm{min}^{-1}$. As fases de composição do catalisador foram obtidas através do programa ( $\mathrm{X}^{\prime}$ Pert HighScore Plus) de acordo com os padrões JCPDS-International Centre For Diffraction Data.

As medidas eletroquímicas foram realizadas numa célula eletroquímica padrão de vidro de um compartimento Pyrex ${ }^{\circledR}$ utilizando um potenciostato/galvanostato Autolab (PGSTA $\mathrm{T} 320 \mathrm{~N}$ ). Todos os testes foram realizados sob atmosfera de $\mathrm{N}_{2}$. Para os experimentos eletroquímicos uma suspensão do catalisador pó em água ultrapura e solução de $0.05 \%$ Náfion ${ }^{\circledR}$ (Sigma-Aldrich) foi preparada. Uma alíquota da suspensão homogeneizada do catalisador foi pipetada sobre uma superfície limpa e polarizada (em 0,6 V) de um eletrodo de diamante dopado com boro (DDB), com grau de dopagem de $800 \mathrm{ppm}$ e área geométrica de $0,54 \mathrm{~cm}^{2}$ e posteriormente seco a $60^{\circ} \mathrm{C}$ em estufa $(\mathrm{SOLAB})$ durante $20 \mathrm{~min}$. Resultando em um filme fino, homogêneo e catalítico como eletrodo de trabalho. Para todos os resultados uma placa de Pt de 1 $\mathrm{cm}^{2}$ foi utilizada como contra eletrodo. $\mathrm{O}$ eletrodo de trabalho que foi utilizado como suporte 
para os compósitos sintetizados foi fixado a uma placa retangular de cobre de $9,5 \mathrm{~cm} \times 1,2 \mathrm{~cm}$. Como eletrodo de referência foi utilizado o eletrodo de hidrogênio preparado na mesma solução (EHMS) imerso em um capilar de Luggin com 9,5 cm de comprimento. As medidas de voltametria cíclica (VC) foram realizadas em eletrólito $0,5 \mathrm{M}$ de $\mathrm{H}_{2} \mathrm{SO}_{4}$.

\section{Resultados e discussões}

A Figura 1 mostra os difratogramas de raios $\mathrm{X}$ para as ligas $\mathrm{PtPb} / \mathrm{C}$, para a série $\mathrm{Pt}_{x} @ \mathrm{~Pb}_{y} / \mathrm{C}$ e Pt/C $/ \mathrm{C}_{\text {MRs }}$. Na Figura 1 (a), em todas as difrações observou-se o pico em $25^{\circ}$, característico do plano (002) de reflexão da estrutura hexagonal do carbono (JCPDS $\mathrm{N}^{\circ}$ 00-0010640) e quatro picos bem definidos associados aos planos (111), (200), (220) e (311), característicos da estrutura cúbica de face centrada (CFC) da Pt.
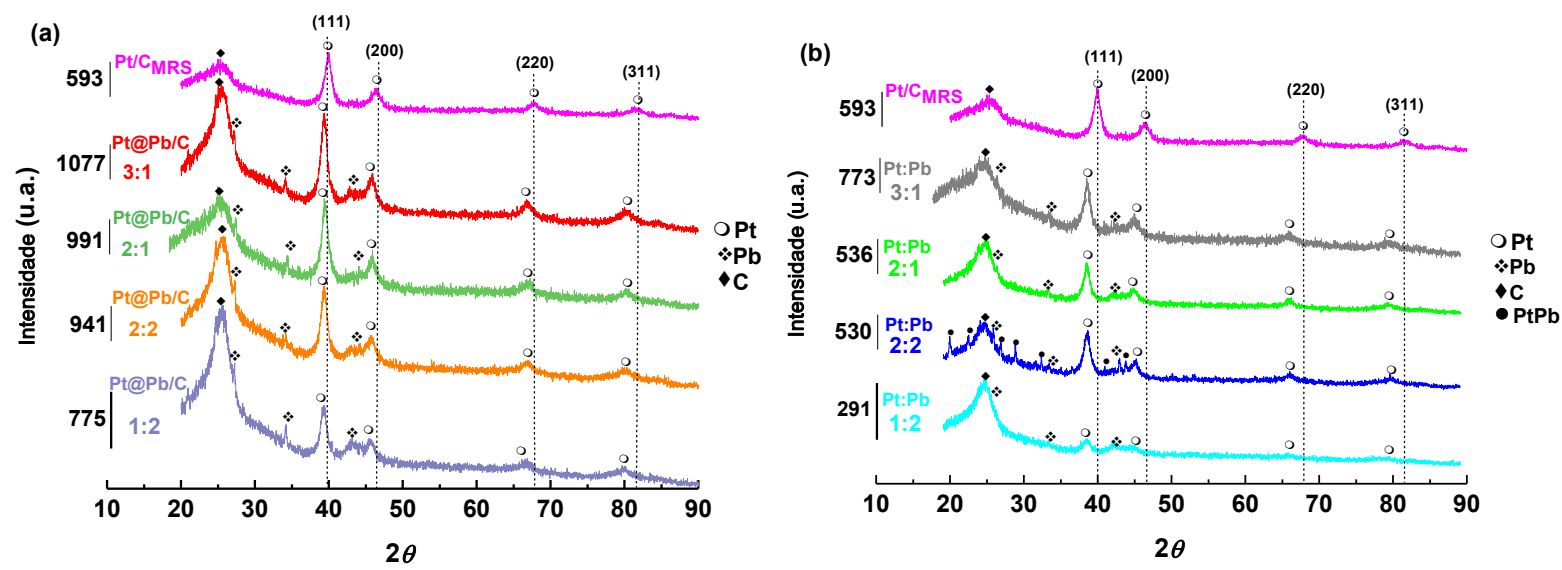

Figura 1. Difratogramas do eletrocatalisador $\mathrm{Pt} / \mathrm{C}_{\mathrm{MRS}}$, e dos eletrocatalisadores preparados da série $\mathrm{Pt}_{x} \mathrm{~Pb}_{y} / \mathrm{C}$, em razões molares de 3:1, 2:1, 1:1 e 1:2: (a) eletrocatalisadores casca-núcleo (b) eletrocatalisadores liga. Os valores mostrados na coluna da esquerda corresponde aos valores do maior pico característicos da rede cristalina da Pt (111).

Para Spinacé et al. (2010) esses picos são observados em valores de $2 \theta=40^{\circ}, 47^{\circ}, 67^{\circ} \mathrm{e}$ $82^{\circ}$, respectivamente. Na Figura 1 (a) os picos observados em valores de $2 \theta=39.4^{\circ}, 45.87^{\circ}$, $66.8^{\circ}$ e $80.08^{\circ}$, apresentam um leve deslocamento para valores menores de $2 \theta$ em relação aos picos da $\mathrm{Pt}_{\text {Mrs. }}$ Resultados publicados por Silva et al. (2010), indicam que a inserção de um segundo metal como núcleo é capaz de modificar levemente o plano de reflexão da Pt, levando os planos da Pt CFC (111, 200, 220 e 311) à menores valores de 20. O tamanho médio das nanopartículas de Pt@Pb/C foram $2.104 \mathrm{~nm}, 2.153 \mathrm{~nm}, 2.378 \mathrm{~nm}, 2.214 \mathrm{~nm}$ e $2.692 \mathrm{~nm}$ para as composições (3:1), (2:1), (1:1), (1:2) e Pt/C, respectivamente. Valores estimados a partir da equação de Debye-Scherer. Os resultados do tamanho médio das nanopartículas $\mathrm{SnO}_{2} @ \mathrm{Pt} / \mathrm{C}$ sintetizadas por Silva et al. (2010) pelo método sol-gel, em comparação, as nanopartículas sintetizadas neste trabalho pelo método de redução sucessiva, mostraram-se com tamanhos maiores em torno de 3 a $16 \mathrm{~nm}$. Para as nanoestruturas ligas (Figura 1b) foi observado também 
um maior deslocamento dos picos referentes aos planos da estrutura CFC da Pt (111, 200, 220 e 311) para ângulos menores de $2 \theta$, resultando em valores de $2 \theta=38.5^{\circ}, 45.02^{\circ}, 65.91^{\circ}$ e $79.43^{\circ}$.

$\mathrm{Na}$ Figura 2, encontram-se as imagens de MET das amostras $\mathrm{Pt}_{3} @ \mathrm{~Pb} / \mathrm{C}, \mathrm{Pt}_{2} @ \mathrm{~Pb} / \mathrm{C}$ e $\mathrm{Pt} @ \mathrm{~Pb} / \mathrm{C}$, bem como os histogramas (obtidos através da contagem individual das partículas). As Figuras apresentam imagens de MET típicas de nanopartículas esféricas, com boa distribuição das nanopartículas no suporte de carbono. As partículas dos catalisadores $\mathrm{Pt}_{3} @ \mathrm{~Pb} \mathrm{e} \mathrm{Pt} @ \mathrm{~Pb}$ suportadas em carbono apresentaram-se em menor quantidade se comparadas à $\mathrm{Pt}_{2} @ \mathrm{~Pb}$, onde obtivemos uma maior quantidade de partículas no suporte, porém, com diâmetros maiores. $\mathrm{O}$ eletrocatalisador $\mathrm{Pt}_{3} @ \mathrm{~Pb}$ apresentou diâmetro médio de partícula de 2,6 nm (Figura 2(a)), enquanto que os eletrocatalisadores $\mathrm{Pt} @ \mathrm{~Pb} / \mathrm{C}$ e $\mathrm{Pt}_{2} @ \mathrm{~Pb} / \mathrm{C}$ (Figura 2(b) e 2(c) apresentaram tamanhos médios de 3,1 e 3,2 nm. Estas diferenças são observadas claramente nos valores dos diâmetros médios $\left(\mathrm{d}_{\mathrm{m}}\right)$ dos histogramas.
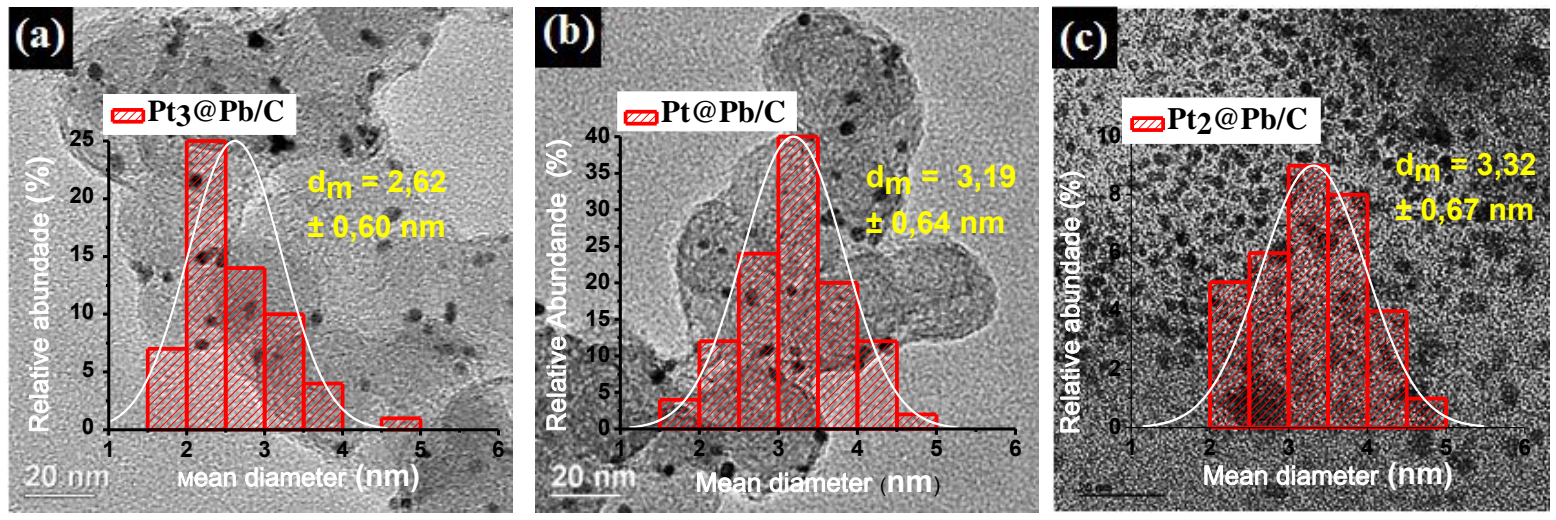

Figura 2. Microscopia eletrônica de transmissão (MET) e histogramas dos eletrocatalisadores (a) $\mathrm{Pt}_{3} @ \mathrm{~Pb} / \mathrm{C},(\mathrm{b}) \mathrm{Pt} @ \mathrm{~Pb} / \mathrm{C}$ e (c) $\mathrm{Pt}_{2} @ \mathrm{~Pb} / \mathrm{C}$.

A Figura 3 mostra o estudo eletroquímico para os eletrocatalisadores sintetizados. A Figura 3 (a) mostra as voltametrias cíclicas em eletrólito de $0,5 \mathrm{~mol} \mathrm{~L}^{-1} \mathrm{H}_{2} \mathrm{SO}_{4}$ e a Figura 3 (b) exibi as voltametrias em eletrólito de $0,5 \mathrm{~mol} \mathrm{~L}^{-1} \mathrm{H}_{2} \mathrm{SO}_{4}+0,5 \mathrm{~mol} \mathrm{~L} \mathrm{~L}^{-1}$ etanol. Já a Figura 3(c) apresenta o estudo comparativo dos eletrocatalisadores de $\mathrm{Pt} / \mathrm{C}, \mathrm{PtPb} / \mathrm{C}$ (3:1) liga e casca-núcleo por cronoamperometria. A Figura 3 (d) indica os valores das pseudodensidades de corrente de equilíbrio obtidas através dos cronoamperogramas paras os eletrocatalisadores da Figura 3 (c).

Os voltamogramas cíclicos da Figura 3 (a) exibiram duas regiões distintas associadas com os processos de adsorção/dessorção de $\mathrm{H}_{\text {upd }}\left(\mathrm{H}^{+}+\mathrm{e}^{-}=\mathrm{H}_{\text {upd }}\right)$ entre $0.05 \mathrm{~V}<\mathrm{E}<0.35 \mathrm{~V}$ e a formação de uma camada de $\mathrm{H}_{2} \mathrm{O}\left(2 \mathrm{H}_{2} \mathrm{O}=\mathrm{OH}_{\mathrm{ad}}+\mathrm{H}_{3} \mathrm{O}+\mathrm{e}^{-}\right)$. O eletrocatalisador $\mathrm{Pt}_{3} @ \mathrm{~Pb} / \mathrm{C}$, exibiu picos de corrente bem definidos associados ao processo de adsorção-dessorção de hidrogênio sobre Pt quando comparados as outras composições, , o que implica somente presença de Pt nas superfícies das partículas. Atribui-se que picos bem definidos nesta região resultam da dessorção de átomos de hidrogênio provenientes de sítios de Pt com rede cristalina bem definida (Tamizhmani et al. 1996). Tamanho médio de $2.62 \mathrm{~nm}$ foi encontrado por MET para o eletrocatalisador com razão molar (3:1) de Pt-Pb. 

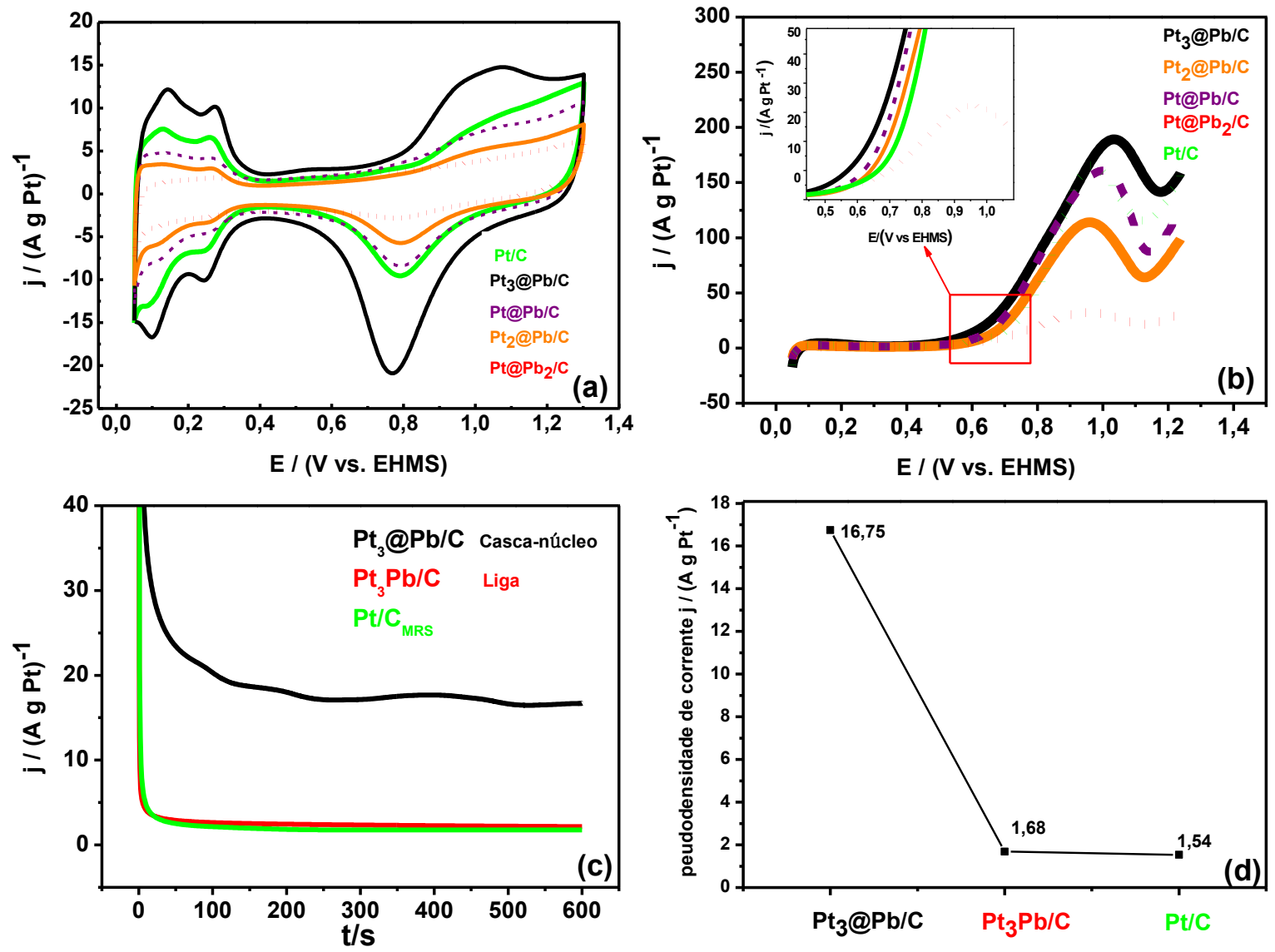

Figura 3. (a) Voltamogramas cíclicos dos catalisadores casca-núcleo e Pt/C. (b) Voltamogramas cíclicos de oxidação de etanol sobre os $\mathrm{Pt} @ \mathrm{~Pb} / \mathrm{C}$ e Pt/C em $0,5 \mathrm{~mol} \mathrm{~L}{ }^{-1} \mathrm{H}_{2} \mathrm{SO}_{4}+0,5 \mathrm{~mol} \mathrm{~L}{ }^{-1}$ etanol, $v=20 \mathrm{mV} \mathrm{s}^{-1}$. (c) Conoamperogramas para os catalisadores $\mathrm{Pt}_{3} @ \mathrm{~Pb} / \mathrm{C}$ (casca-núcleo), $\mathrm{Pt}_{3} \mathrm{~Pb} / \mathrm{C}$ (liga) e Pt/C. A inserção indica o início de oxidação de etanol. (d) Comparação da pseudodensidade de corrente de equilíbrio para os catalisadores testados por cronoamperometria.

As cargas correspondentes à região de adsorção/dessorção $\mathrm{H}_{\text {upd }}$ após a correção da dupla camada e assumindo um valor de $210 \mu \mathrm{C} \mathrm{cm}^{-2}$ para a formação de uma monocamada de hidrogênio adsorvido sobre a superfície de Pt (Watanabe et al. 1989), foram calculadas como sendo $633.25 \mathrm{~m}^{2} \mathrm{~g}^{-1}$ para o $\mathrm{Pt}_{3} @ \mathrm{~Pb} / \mathrm{C}$ e $323.21 \mathrm{~m}^{2} \mathrm{~g}^{-1} \mathrm{Pt} / \mathrm{C}$. Assim, a ECSA (superfície exposta eletroquimicamente ativa) das nanopartículas $\mathrm{Pt}_{3} @ \mathrm{~Pb} / \mathrm{C}$ mostra-se duas vezes maior (valor calculado de $51 \%$ ) quando comparada com o Pt/C $\mathrm{C}_{\mathrm{MRS}}$. Os valores de ECSA obtidos para os demais eletrocatalisadores da série $\mathrm{Pt}_{x} @ \mathrm{~Pb}_{y} / \mathrm{C}$ foram (207.20 m $\left.\mathrm{g}^{-1}\right) \mathrm{Pt}_{2} @ \mathrm{~Pb} / \mathrm{C},\left(259.14 \mathrm{~m}^{2}\right.$ $\left.\mathrm{g}^{-1}\right) \mathrm{Pt} @ \mathrm{~Pb} / \mathrm{C}$ e $\left(103.55 \mathrm{~m}^{2} \mathrm{~g}^{-1}\right) \mathrm{Pt} @ \mathrm{~Pb}_{2} / \mathrm{C}$.

$\mathrm{Na}$ Figura 3 (b) as estruturas casca-núcleo com 25,0\% ( $\left.\mathrm{Pt}_{3} @ \mathrm{~Pb}\right), 33,3 \%\left(\mathrm{Pt}_{2} @ \mathrm{~Pb}\right)$ e $50,0 \%(\mathrm{Pt} @ \mathrm{~Pb})$ de $\mathrm{Pb}$ apresentaram potenciais de início de oxidação $\left(\mathrm{E}_{\mathrm{i}}\right)$ inferiores $(0,52 \mathrm{~V}, 0,61$ $\mathrm{V}$ e $0,58 \mathrm{~V}$ versus EHMS) para um valor de $j=7\left(\mathrm{~A} \mathrm{~g} \mathrm{Pt}^{-1}\right)$, em relação ao catalisador com 66,6 $\%$ do metal não-nobre e ao catalisador com $100 \%$ de Pt, com valores de $\mathrm{E}_{\mathrm{i}}$ em torno de $0,64 \mathrm{~V}$; 
0,63 V versus EHMS, respectivamente. A Figura 3 (c) mostra os cronoamperogramas dos catalisadores $\mathrm{Pt}_{3} @ \mathrm{~Pb} / \mathrm{C}$ (casca-núcleo), $\mathrm{Pt}_{3} \mathrm{~Pb} / \mathrm{C}$ (liga) com menor valor de $\mathrm{E}_{\mathrm{i}}$ e $\mathrm{Pt} / \mathrm{C}$ realizados em potencial de 0,6 V versus EHMS. Após um decaimento inicial, os valores de pseudodensidade de corrente permanecem constantes, na seguinte ordem de atividade $\mathrm{Pt}_{3} @ \mathrm{~Pb} / \mathrm{C}>$ $\mathrm{Pt}_{3} \mathrm{~Pb} / \mathrm{C}>\mathrm{Pt} / \mathrm{C}$. Na Figura 3 (d) é possível observar aumento na atividade catalítica para $\mathrm{Pt}_{3} @ \mathrm{~Pb} / \mathrm{C}$, esse efeito é atribuído ao aumento na área superficial de Pt (Kristian e Wang 2008), e/ou a mudança no nível da banda " $d$ " neste material podem ser sugeridas como possíveis explicações na oxidação de etanol.
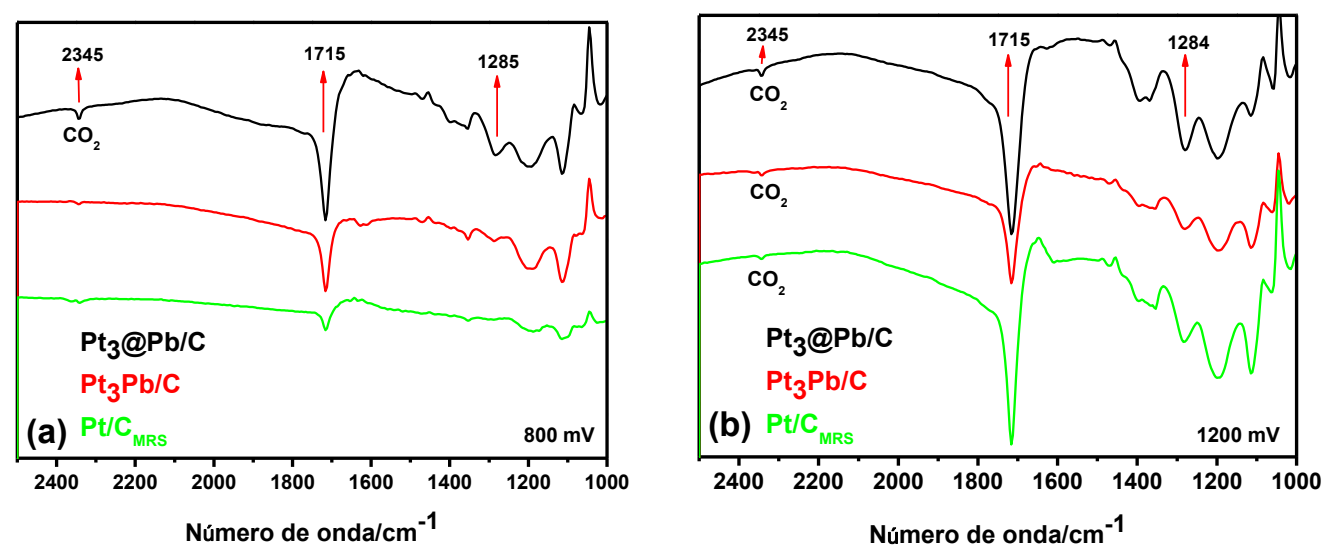

Figura 4. Espectros de infravermelho coletados em $800 \mathrm{mV}$ (a) e $1200 \mathrm{mV}$ (b) $\mathrm{Pt}_{3} @ \mathrm{~Pb} \mathrm{C}$ (casca-núcleo), $\mathrm{Pt}_{3} \mathrm{~Pb} / \mathrm{C}$ (liga) e $\mathrm{Pt} / \mathrm{C}$ em solução de $\mathrm{H}_{2} \mathrm{SO}_{4} 0,5 \mathrm{~mol} \mathrm{~L}^{-1} \mathrm{CH}_{3} \mathrm{CH}_{2} \mathrm{OH} 0,5$ mol L${ }^{-1}$.

$\mathrm{Na}$ Figura 4, a banda em $2345 \mathrm{~cm}^{-1}$ corresponde ao pico de vibração de estiramento assimétrico do $\mathrm{CO}_{2}$, isso reflete a clivagem da ligação $\mathrm{C}-\mathrm{C}$ na oxidação do etanol. A banda em $\sim 1715 \mathrm{~cm}^{-1}$ é a vibração de alongamento da ligação $\mathrm{C}=\mathrm{C}$ em ácido acético e/ou acetaldeído e a banda em $1285 \mathrm{~cm}^{-1}$ é a característica de absorção de $\mathrm{C}-\mathrm{O}$ em ácido acético, geralmente usada para a análise quantitativa de ácido acético. Os FTIRs da Figura 4 (a) mostram bandas de $\mathrm{CO}_{2}$ iniciando a partir de $0,8 \mathrm{~V}$ para $\mathrm{Pt}_{3} @ \mathrm{~Pb} / \mathrm{C}$, enquanto que para os demais catalisadores conversões a $\mathrm{CO}_{2}$ somente foram observadas em potencial $1.2 \mathrm{~V}$.

\section{CONLUSÃO}

Foi demonstrado a possibilidade de estruturas casca-núcleo com alta atividade eletrocatalítica na oxidação de etanol sintetizadas com baixa carga de $\mathrm{Pt}$ ( $25 \%$ inferior a Pt/C). A partir de imagens de MET, determinou diâmetros médios variando entre 1.5-5 nm. De acordo com experimentos voltamétricos e testes cronoamperométricos, a estrutura $\mathrm{Pt}_{3} @ \mathrm{~Pb} / \mathrm{C}$ apresentou um aumento da atividade eletrocatalítica durante a oxidação de etanol comparado com $\mathrm{Pt} / \mathrm{C}_{\mathrm{MRS}}$. $\mathrm{O}$ efeito deste material na oxidação de etanol pode provavelmente ser explicado pelo aumento da área de superfície eletroquímica e/ou uma mudança no nível de banda " $d$ ", como sugerido para camadas metálicas em estruturas casca-núcleo estudadas na literatura. Resultados demonstrados indicam que o $\mathrm{Pt}_{3} @ \mathrm{~Pb} / \mathrm{C}$ pode ser um material promissor em células a combustível de etanol direto. 


\section{REFERÊNCIAS}

CHEN Y.; YANG F.; DAI Y.; WANG W.; CHEN S. Ni@ Pt Core-Shell nanoparticles: synthesis, structural and electrochemical properties. J. Phys. Chem. C, v. 9 p. 1645-1649, 2008.

GARAM, PARK.; DAEHA, SEO.; JONGWOOK J.; SEOL, R.; HYUNJOON S. Shape Evolution and Gram-Scale Synthesis of Gold@Silver Core_Shell Nanopolyhedrons, J.Phys. Chem., v. 17, 2011.

GENG, D.; MATSUKI D.; WANG, J.; KAWAGUCHI, T.; SUGIMOTO, W.; TAKASU, Y. Activity and durability of ternary PtRuIr/C for methanol electro-oxidation. J. Electrochem. Soc., v. 402, p. 397-402, 2009.

LIANG, W. ;YUSUKE, YAMAUCHI. Strategic Synthesis of Trimetallic Au@Pd@Pt Core_Shell Nanoparticles from Poly(vinylpyrrolidone)-Based Aqueous Solution toward Highly Active Electrocatalysts. Chem. Mat., v. 23, p. 2457-2465, 2011.

KAJIKAWA, Y.; YOSHIKAWA, J.; TOKUDA, Y.; MATSUSHIDA, Y. Tracking emerging technology in energy research: Toward a roadmap for sustainable energy. Technol. Forecast Soc. Change, v. 75, p. 771-782, 2008.

$\mathrm{KOH}$, S. STRASSER, P. Electrocatalysis on bimetallic surfaces: modifying catalytic reactivity for oxygen reduction by voltammetric surface dealloying. J. Am. Chem. Soc., v. 5, p. 12624-12625, 2007.

KRISTIAN N, WANG, X. Pt $\mathrm{Phell}_{\text {she }}-\mathrm{Au}_{\text {core }} / \mathrm{C}$ electrocatalyst with a controlled shell thickness and improved Pt utilization for fuel cell reactions. Electrochem. Commun., v.5, p. 12-15, 2008.

SASAKI.K.; KUTTIYIEL, K. A.; BARRIO, L.; SU, D.; FRENKEL, A. I.; MARINKOVIC, N.; MAHAJAN, D.; ADZIC, R. R. Carbon-Supported IrNi Core-Shell Nanoparticles: Synthesis Characterization, and Catalytic Activity. J. Phys. Chem., v. 115, p.9894-9902, 2011.

SILVA, J. C. M.; DE SOUZA, R. F. B.; PARREIRA, L. S.; NETO, E. T.; CALEGARO, M. L.; SANTOS, M. C. Ethanol Oxidation Reactions Using $\mathrm{SnO}_{2} @ \mathrm{Pt} / \mathrm{C}$ as an Electrocatalyst. Appl. Catal. B: Environ., v. 99, p. 265-271, 2010.

SPINACÉ, E. V.; DIAS, R. R.; BRANDALISE, M.; LINARDI, M.; NETO, A. O. Electrooxidation of ethanol using $\mathrm{PtSnRh} / \mathrm{C}$ electrocatalysts prepared by alcohol - reduction process, Ionics, v. 16, p. 91-95, 2010.

TAMIZHMANI, G.; DODELET, J. P.; GUAY, D. Crystallite Size Effects of Carbon-Supported Platinum on Oxygen Reduction in Liquid Acids, J. Electrochem. Soc., v. 143, p.18-23, 1996.

WATANABE, M.; SEI, H.; STONEHART, P. The Influence of Platinum Crystallite Size on the Electroreduction of Oxygen, J. Electroanal. Chem., v. 261, p. 375-387, 1989.

ZHOU, W. J.; SONG, S.Q.; LI, W. Z.; ZHOU, Z. H.; SUN, G. Q.; XIN, Q.; DOUVARTZIDES, S.; TSIAKARAS, P. Direct ethanol fuel cells based on PtSn anodes: the effect of Sn content on the fuel cell performance. J. Power Sources, v. 140, p. 50-58, 2005. 